\title{
Forward alteration rate measurement using the Stirred Reactor - Coupon Analysis (SRCA) technique
}

\author{
BENJAMIN PARRUZOT ${ }^{1, *}$, JOSEPH RYAN ${ }^{1, *}$, JOELLE \\ REISER ${ }^{1}$, XIAONAN LU ${ }^{1}$, SEBASTIEN KERISIT ${ }^{1}$, SCOTT \\ COOLEY $^{1}$, JEFF BONNETT ${ }^{1}$, LORRAINE SEYMOUR ${ }^{1}$, \\ DANiEl PRATHER ${ }^{1}$, MATT ASMUSSEN ${ }^{1}$, JOHN VIENNA ${ }^{1}$ \\ ${ }^{1}$ Pacific Northwest National Laboratory, Richland, WA, USA \\ (*correpondence: benjamin.parruzot@pnnl.gov, \\ joe.ryan@pnnl.gov)
}

Multiple methods are commonly used to determine the forward rate of silicate glass alteration, including Single Pass Flow Through (SPFT), static dissolution testing in very dilute conditions, and soxhlet testing. Each of these methods presents limitations, such as the ability to quantify elements in solutions, the required sampling frequency or total number of samples, the temperature ranges that can be used, or the accurate determination of the glass surface area $[1,2]$.

The Stirred Reactor - Coupon Analysis (SRCA) technique consists of altering partially masked monolithic samples (coupons) in a large amount of agitated solution in turbulent flow conditions at controlled $\mathrm{pH}$ and temperature. The large volume of solution relative to the surface area corroded and turbulent flow leads to reliably dilute conditions at the sample surface. The surface of the monoliths is analyzed by optical profilometry to determine the height difference between the masked surface and the surface exposed to the fluid. This height difference is used to calculate alteration rate.

A variety of borosilicate glasses have been subjected to SRCA testing, demonstrating the ability to measure alteration rates that span several orders of magnitude $\left(0.003\right.$ to $100 \mathrm{~g} \cdot \mathrm{m}^{-}$ $\left.{ }^{2} \cdot \mathrm{d}^{-1}\right)$. Two studies on the effect of glass composition on forward alteration rate will be discussed. The first includes two subsets of 6-component glasses aimed at understanding the impact of $\mathrm{Al}$ on glass alteration processes. The forward rate data acquired as part of this study will be compared to existing models and molecular dynamics simulations. The second dataset is a statistically-designed matrix of 24 simulated lowactivity nuclear waste glasses aimed at isolating the effects of major oxide components (e.g., $\mathrm{Al}_{2} \mathrm{O}_{3}, \mathrm{SiO}_{2}, \mathrm{~B}_{2} \mathrm{O}_{3}, \mathrm{CaO}$, $\mathrm{Na}_{2} \mathrm{O} \ldots$..) on forward rate model parameters (rate constant, activation energy, and $\mathrm{pH}$ power law coefficient ). Statistical analyses were performed to identify composition-parameter correlations.

[1] Neeway et al. (2018) Geochim. Cosmochim. Acta 226, 132148. [2] Fournier et al. (2016) J. Nucl. Mat. 476 140-154. 